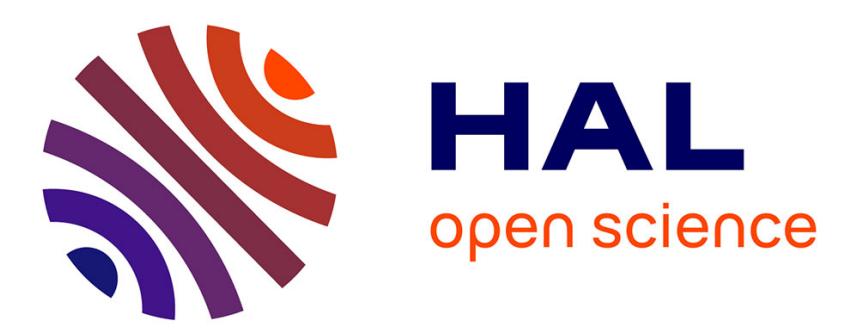

\title{
Mixed-Signal PI Controller in Current-Mode DC-DC Buck Converter for Automotive Applications
}

Yasser Moursy, Raouf Khalil, Sergio Lecce, Vanni Poletto, Ramy Iskander, Marie-Minerve Louërat

\section{- To cite this version:}

Yasser Moursy, Raouf Khalil, Sergio Lecce, Vanni Poletto, Ramy Iskander, et al.. Mixed-Signal PI Controller in Current-Mode DC-DC Buck Converter for Automotive Applications. IEEE International Symposium on Circuits and Systems (ISCAS'16), May 2016, Montréal, Canada. pp.1610-1613, 10.1109/ISCAS.2016.7538873 . hal-01325114

\section{HAL Id: hal-01325114 https://hal.science/hal-01325114}

Submitted on 1 Jun 2016

HAL is a multi-disciplinary open access archive for the deposit and dissemination of scientific research documents, whether they are published or not. The documents may come from teaching and research institutions in France or abroad, or from public or private research centers.
L'archive ouverte pluridisciplinaire HAL, est destinée au dépôt et à la diffusion de documents scientifiques de niveau recherche, publiés ou non, émanant des établissements d'enseignement et de recherche français ou étrangers, des laboratoires publics ou privés. 


\title{
Mixed-Signal PI Controller in Current-Mode DC-DC Buck Converter for Automotive Applications
}

\author{
Yasser Moursy*, Raouf Khalil ${ }^{*}$, Sergio Lecce ${ }^{\dagger}$ Vanni Poletto $^{\dagger}$, Ramy Iskander* and Marie-Minerve Louërat* \\ ${ }^{*}$ Sorbonne Universités, UPMC Univ Paris 06, UMR 7606, LIP6, F-75005, Paris, France \\ ${ }^{\dagger}$ ST Microelectronics, Cornaredo, Italy \\ Email: yasser.moursy@lip6.fr
}

\begin{abstract}
This paper proposes a fully-integrated solution for the PI compensation circuits in current-mode DC-DC converters used in automotive applications. In such applications, the switching frequencies are low and hence conventional PI compensation circuits employ large capacitors. The proposed analog/mixedsignal PI comprises an analog proportional amplifier and a digital integrator. The analog proportional amplifier provides the required response time and maintains system stability. The digital integrator block is used to eliminate the output voltage steady-state error. Simulink is used to model the proposed DCDC buck converter on the system level. The proposed system is verified by full system level simulation. The digital part is synthesized with HDL coder and laid-out using $0.35 \mu \mathrm{m}$ CMOS technology. The estimated silicon area of the proposed solution is about $0.1 \mathrm{~mm}^{2}$. This result highlights the simplicity and the capacity for integration of the proposed control loop along with its potential for seamless implementation into pre-existing solutions with minor modifications.
\end{abstract}

\section{INTRODUCTION}

Switching mode power supplies (SMPS) are widely used in automotive applications. They provide stable and robust power supplies with different voltages for the diverse electronic circuits on-board. The switched-mode power supplies are classified based on the feedback control loop as voltagemode control or current-mode control. The former is based on sensing the output voltage. Such control loop contains two poles that are conventionally compensated by ProportionalIntegral-Differential (PID) circuit. The main function of this compensation circuit is to maintain the desired loop gain crossover frequency and phase margin, hence preserving the loop stability. In addition to complex control dynamics, the voltage-mode SMPS needs techniques to limit the inductor current during start-up (i.e., soft-start techniques) and overload conditions (i.e., current sensors to sense the inductor current). On the other hand, the current-mode is based on sensing the output voltage and the inductor current. The currentmode loop has only one dominant pole and another pole near the switching frequency [1]-[3]. The key advantages of the current-mode control are simple dynamics due to the presence of one pole and inherited current limiting. Sensing the inductor current with minimum losses is the major challenge for such control loops.

The compensation circuit can be purely analog or digital. The analog compensation circuits are commonly used for their stability and minimum delay. However, in high-voltage automotive applications, the switching frequencies are in the range of hundreds of $\mathrm{kHz}$ [4] in order to limit electromagnetic interference (EMI) emissions. In such low frequencies, the implementation of proportional-integral (PI) compensation circuit requires capacitance in order of $\mathrm{nF}$ which cannot be integrated.

Digital compensation circuits allow the implementation of complex control schemes and the dynamic control of the systems [5]. However, digital control suffers from signal processing delay and hence it requires a relatively high clock frequencies with respect to the switching frequencies [6][9]. Higher clock frequencies increase the electromagnetic emissions levels, which are highly undesirable for automotive applications. Besides, the implementation of Analog-to-Digital Converter (ADC) and Digital-to-Analog Converter (DAC) at such high frequency is power hungry solution.

The aim of this paper is to propose an analog-mixed approach of PI compensator for current-mode control used in buck DC-DC converter adequate for automotive applications. In this proposed system, the proportional part is implemented as analog circuit to maintain the required crossover frequency. The integrator part is implemented in digital domain to compensate the steady state error. The analog-mixed solution relaxes clock speed requirements on the ADC, DAC, and digital circuits and can be fully integrated.

The paper is organized as follows, Section II describes the conventional control architecture for the current-mode SMPS. Section III shows the proposed mixed PI control system operation and implementation. Simulation results are reported in Section IV. Section V concludes the paper.

\section{CONVEnTIONAL CONTROL FOR CURRENT-MODE BUCK CONVERTERS}

A simplified peak current-mode control DC-DC buck converter is shown in Figure 1. To sense the output voltage $V_{\text {out }}$, it is scaled by a divider circuit $H_{\text {divider }}$ and compared to a reference voltage $V_{\text {ref }}$ providing an error signal $v_{e}(t)$. An analog PI compensator is used to integrate and amplify the error signal and generate the control signal $v_{c}(t)$. This $v_{c}(t)$ is converted into a current signal to ease the subtraction of the compensation ramp signal. The compensation ramp signal 


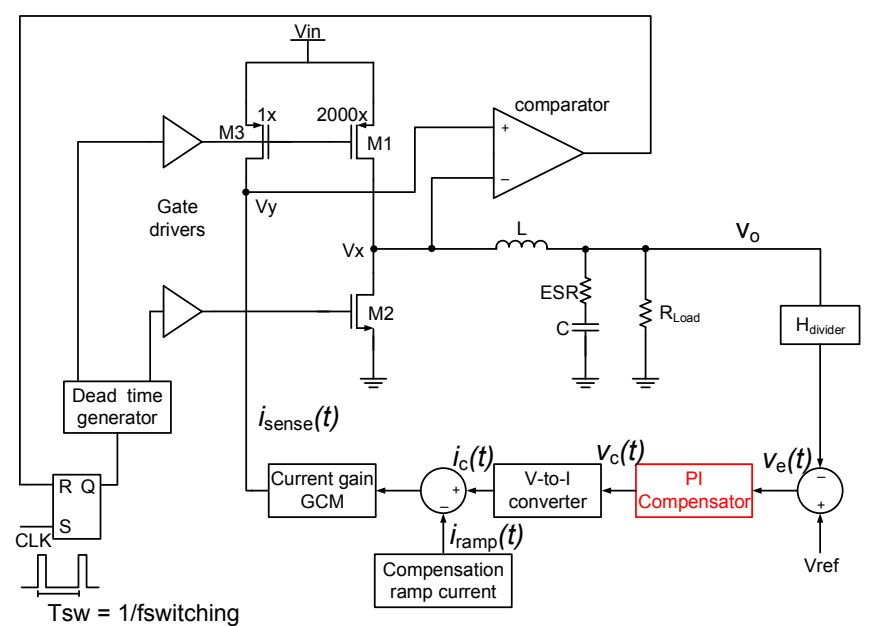

Fig. 1: Simplified architecture of the used current-mode buck converter

is used in order to prevent the subharmonic oscillations when the duty cycle exceeds $50 \%$ [2].

For the inductor current sensing, transistor M3 acts as a sense FET. Its aspect ratio is a portion of high-side (HS) switch M1. A current gain is used to achieve reasonable ratios between the sense FET and the high-side switch. The comparator turns off the HS switch when $V_{y}>V_{x}$ but $V_{y}=V_{\text {in }}-i_{\text {sense }}(t) \times R_{\mathrm{M} 3}$ and $V_{x}=V_{\text {in }}-i_{L}(t) \times R_{\mathrm{M} 1}$ where $R_{\mathrm{M} 1}$ and $R_{\mathrm{M} 3}$ are the on resistance of the HS switch M1 and the sense FET M3, respectively.

Hence, the condition for switching the HS switch off can be expressed as:

$$
i_{L}>i_{\text {sense }} \times \frac{R_{\mathrm{M} 3}}{R_{\mathrm{M} 1}}
$$

In this example, the ratio $R_{\mathrm{M} 3} / R_{\mathrm{M} 1}$ is 2000 . Hence, $i_{\text {sense }}$ can be scaled down 2000 times compared to $i_{L}$. The switching frequency is determined by the clock (CLK) used to turn on the HS switch each switching cycle.

To illustrate the main issue concerning the analog PI circuit, a conventional PI circuit is shown in Figure 2 [10]. The transfer function is given as

$$
A(s)=\frac{\widehat{v} c}{H_{\text {divider }} \widehat{v o}}=g_{m} R_{z} \frac{s+1 /\left(C_{z} R_{z}\right)}{s+1 /\left(C_{z} R_{o}\right)}, \text { for } R o>>R z
$$

From this transfer function, a proportional gain of $g_{m} R_{z}$ is designed to get the desired loop gain crossover frequency. The crossover frequency is set to be less or equal to $20 \%$ of the switching frequency in order to avoid amplifying switching ripples. A zero located at $\omega_{z}=1 /\left(C_{z} R_{z}\right)$ compensates the dominant pole of loop gain approximately at $\omega_{p}=1 /\left(R_{\text {load }}(\max ) \times C.\right)$. If the switching frequency $f_{\text {switching }}$ is $330 \mathrm{kHz}$, the crossover frequency is designed to be $40 \mathrm{kHz}$. In order not to affect the phase margin, the low frequency zero

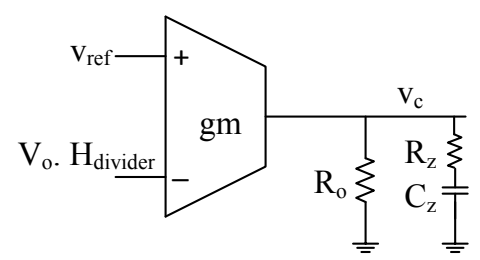

Fig. 2: PI compensator using operational transconductance amplifier

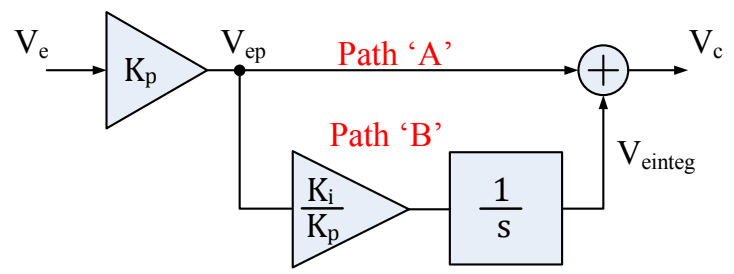

Fig. 3: PI compensator block diagram

$f_{z}$ should be located at least less than $1 / 10$ of the crossover frequency, i.e., $f_{z}=4 \mathrm{kHz}$. For $R_{z}=10 \mathrm{k} \Omega$, the capacitor needed $C_{z}$ is about $4 \mathrm{nF}$ which is an off chip component that increases the cost of the converter.

\section{Proposed AnAlog-Mixed PI CONTROL For CURRENT MODE BUCK CONVERTERS}

The analog PI system level is shown in figure 3. The block diagram can be separated in two paths:

1) Path 'A' which represents the proportional component $\left(V_{e p}=K_{p} V_{e}\right.$ ) of the PI circuit used to set the crossover frequency of the control-to-output loop gain.

2) Path 'B' which represents the integral component $\left(V_{\text {einteg }}\right)$ in the PI circuit with gain $\left(K_{i} / K_{p}\right)$.

The transfer function of the ideal system versus the transfer function of the circuit level assuming infinite output resistance is given by:

$$
\frac{\widehat{v}_{\text {out }}}{\widehat{v}_{\text {in }}}=g_{m} \cdot R_{z} \frac{s+1 /\left(C_{z} R_{z}\right)}{s}=K_{p} \cdot \frac{s+K_{i} / K_{p}}{s}
$$

From equation 3 , the zero corner frequency depends on the value of the capacitor $C_{z}$ which is located in path 'B'. The proposed solution is to implement the proportional path ' $\mathrm{A}$ ' in analog amplifier and to implement the integral path ' $\mathrm{B}$ ' using a digital integrator. Figure 4 shows the integral path with a certain gain to have a response comparable to the analog integrator. Hence, the off chip capacitor $C_{z}$ will not be used.

The integral path consists of an ADC, a digital integrator and a DAC. First, the ADC is realized by a discrete-time single bit $\Sigma \Delta$ modulator. The $\Sigma \Delta$ modulator is selected to simplify the design and reduce the silicon area. Since the signal-ofinterest is the error signal $v_{e}(t)$ which is a low frequency 


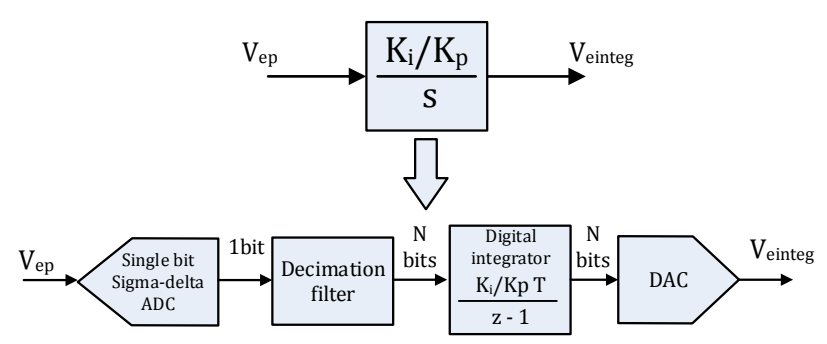

Fig. 4: Integral path proposed representation

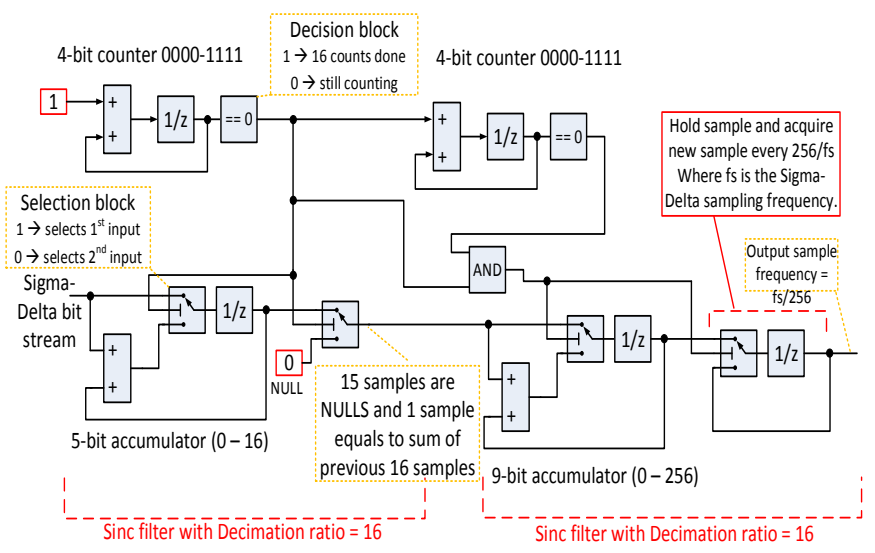

Fig. 5: Decimation block implementation using fixed point representation $(\mathrm{DR}=256)$

signal, the $\Sigma \Delta$ sampling frequency can be minimized. However, increasing the sampling frequency results in reducing the integrator response time and consequently, the resolution is enhanced but the power consumption is increased. Thus, a trade-off exists between the sampling frequency and integrator response time. The decimation block is responsible for down sampling the high frequency $\Sigma \Delta$ output bit-stream. If the sampling frequency is $f_{s}$ and the decimation ratio is $D R$, then the output data rate is $f_{D}=f_{s} / D R$ with resolution $\log _{2}(D R)$. The integrator response time is equal to $1 / f_{D}$. An example for decimation filter architecture is shown in Figure 5. It implements a $\operatorname{sinc} c^{2}$ filter using fixed-point blocks. This implementation could be ported directly to VHDL then synthesized to generate the layout.

In the continuous time integrator, the integrator gain sets the crossover frequency which also determines the position of the PI zero frequency as shown in Figure 6. Similarly, the discrete time integrator gain factor is defined as $\left(K_{i} / K_{p} T\right)$ where $\mathrm{T}$ is the sampling time. As the gain $\left(K_{i} / K_{p} T\right)$ increases, its crossover frequency increases. Hence, if the integrator crossover frequency approaches the loopgain crossover frequency, it may deteriorate the phase margin of the loop and affect the stability. Consequently, the integrator gain should be adjusted to locate the zero corner frequency lower than $1 / 10$ of the loopgain crossover frequency and lower than the dominant
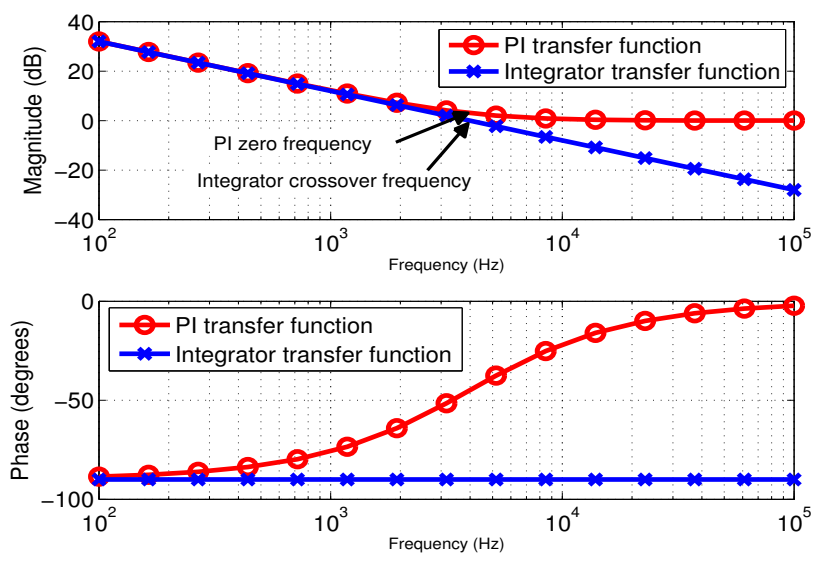

Fig. 6: Integrator and PI compensator transfer functions

pole frequency.

In the system level model, the gain is realized by a shift right register in order to reduce the system complexity. However, this limits the values of the gain to $2^{-N}$, where $\mathrm{N}$ is the number of shifted bits. Because of this constraint the exact equivalence between the continuous and discrete integrator might not be feasible.

\section{Simulation RESUlts}

The specifications of the proposed buck DC-DC converter are shown in table I. System level simulations are performed

TABLE I: DC-DC buck converter specifications

\begin{tabular}{|l|c||l|c|}
\hline$V_{\text {in }}$ & $5-15 \mathrm{~V}$ & $V_{\text {out }}$ & $2.5 \mathrm{~V}$ \\
\hline$I_{\text {out }}$ & $0.05-0.6 \mathrm{~A}$ & $f_{\text {switching }}$ & $330 \mathrm{kHz}$ \\
\hline Inductor value & $105 \mu \mathrm{H}$ & Capacitor Value & $33 \mu \mathrm{F}$ \\
\hline $\begin{array}{l}\text { Inductor series } \\
\text { resistance DCR }\end{array}$ & $50 \mathrm{~m} \Omega$ & $\begin{array}{l}\text { Capacitor series } \\
\text { resistance ESR }\end{array}$ & $35 \mathrm{~m} \Omega$ \\
\hline
\end{tabular}

to estimate the control-to-output transfer function and the loopgain at minimum load current $\left(I_{\text {load }}=0.05 \mathrm{~A}\right)$. The transfer function shows the presence of two poles and zero due to series resistance of the capacitor (ESR). The loopgain crossover frequency is selected to be $40 \mathrm{kHz}$, consequently, the proportional amplifier gain $(\mathrm{Kp})$ is found to be 10 . The dominant pole of the loopgain is estimated from the modeled transfer functions to vary from $300 \mathrm{~Hz}$ to $1.4 \mathrm{kHz}$ when the load current changes from 0.05 to $0.6 \mathrm{~A}$, respectively. Hence, the zero corner frequency of the PI compensator is selected to be $300 \mathrm{~Hz}$.

A single bit $\Sigma \Delta$ modulator is used with a sampling frequency of $5.28 \mathrm{MHz}$. This sampling frequency is used to achieve a high resolution after decimation. The decimation ratio is 256 and the number of bits at the output is 8 bits. Hence, the integrator response time equals to $45 \mu \mathrm{s}$ which results in an acceptable transient response for the system.

Figure 7 shows the output voltage at minimum load current with only proportional amplifier and with PI compensator. The 


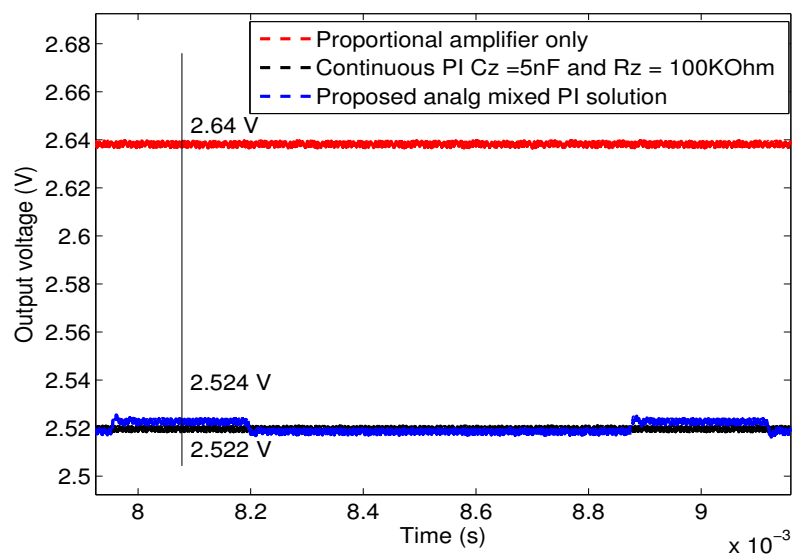

Fig. 7: Steady-state output voltage at $\left(I_{\text {load }}=0.05 A\right)$ (a)Proportional amplifier only, (b) Analog PI compensation, (c) proposed analog-mixed PI compensation

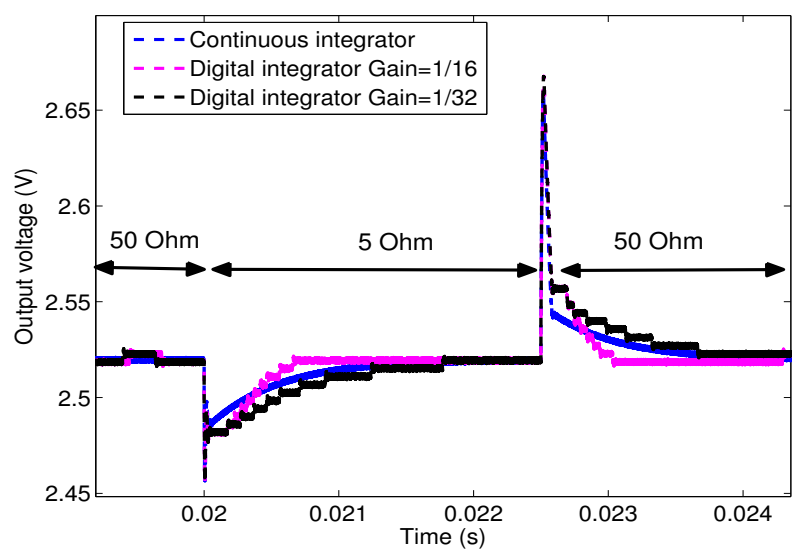

Fig. 8: Load step response $I_{\text {load }}=0.05 \mathrm{~A}$ to $0.5 \mathrm{~A}$ showing the effect of changing the digital integrator gain

PI compensator eliminates the steady-state error voltage and keeps the error in output voltage within $3 \%$. The proposed circuit shows idle pattern oscillation due to the presence of relatively low DC voltage at the input of the $\Sigma \Delta$ ADC. This pattern is limited to a very small value that can be tolerated by the system.

For the proposed solution, the integrator gain $\left(K_{i} / K_{p} T\right)$ can be changed to control the settling time of the output voltage. In Figure 8, the output voltage response due to a pulse change in the load resistance from $50 \Omega$ to $5 \Omega$ for different integrator gains. As the integrator gain reduces, the settling time increases.

In order to estimate the area of the proposed system, VHDL code for the digital part is generated directly from the Simulink using the HDL coder tool. Then, it is synthesized and laid out using $0.35 \mu \mathrm{m}$ HV CMOS technology. The estimated area is about $0.05 \mathrm{~mm}^{2}$ and the reported number of gates used is 180 gates, with an estimated power consumption of $0.35 \mathrm{~mW}$ at a supply voltage of $5 \mathrm{~V}$. An estimation for the area of the sigma-delta ADC is $0.017 \mathrm{~mm}^{2}$ and the DAC area is about $0.034 \mathrm{~mm}^{2}$. Hence, the total estimated area is about $0.1 \mathrm{~mm}^{2}$. These metrics highlight the simplicity and the integration potential of the proposed control loop.

\section{CONCLUSION}

An integrated analog-mixed PI compensation circuit has been proposed for automotive applications. The proposed system attempts to alleviate the usage of an external capacitor in the pure analog compensation circuit along with relaxing clock speed constraints of the digital circuit in the fully digital PI solutions. Simulation results prove the functionality of the proposed system. The digital circuit occupies an area of $0.05 \mathrm{~mm}^{2}$ in the system and its power consumption can be neglected. The whole solution area is estimated to be approximately $0.1 \mathrm{~mm}^{2}$. The proposed solution can be easily mapped to different DC-DC buck converters specifications.

\section{ACKNOWLEDGMENT}

This work has been sponsored by the European commission under the European FP7 AUTOMICS project.

\section{REFERENCES}

[1] M. K. Kazimierczuk, Pulse-width modulated DC-DC power converters. John Wiley \& Sons, 2008

[2] R. W. Erickson and D. Maksimovic, Fundamentals of power electronics. Springer, 2001

[3] S. Chattopadhyay and S. Das, "A digital current-mode control technique for DC-DC converters," Power Electronics, IEEE Transactions on vol. 21, no. 6, pp. 1718-1726, Nov 2006.

[4] B. Murari, F. Bertotti, and G. A. Vignola, Smart power ICs: technologies and applications. Springer Science \& Business Media, 2002, vol. 6.

[5] D. Maksimović, R. Zane, and R. Erickson, "Impact of digital control in power electronics," in Power Semiconductor Devices and ICs, Proceedings. ISPSD'04. The 16th International Symposium on. IEEE, 2004, pp. 13-22.

[6] A. Zhao, A. A. Fomani, and W. T. Ng, "One-step digital dead-time correction for DC-DC converters," in Applied Power Electronics Conference and Exposition (APEC), 2010 Twenty-Fifth Annual IEEE. IEEE, 2010, pp. 132-137.

[7] H. Ahmad and B. Bakkaloglu, "A digitally controlled DC-DC buck converter using frequency domain ADCs," in Applied Power Electronics Conference and Exposition (APEC), 2010 Twenty-Fifth Annual IEEE. IEEE, 2010, pp. 1871-1874.

[8] A. Parayandeh and A. Prodić, "Programmable analog-to-digital converter for low-power DC-DC SMPS," Power Electronics, IEEE Transactions on, vol. 23, no. 1, pp. 500-505, 2008.

[9] S. Cheng, S. Yao, G. Jin, and W. Ng, "Digital controlled dead-time for tri-mode buck-boost dc-dc converters," in Solid-State and Integrated Circuit Technology (ICSICT), 2014 12th IEEE International Conference on. IEEE, 2014, pp. 1-3.

[10] C. F. Lee and P. K. Mok, "A monolithic current-mode CMOS DC-DC converter with on-chip current-sensing technique," Solid-State Circuits, IEEE Journal of, vol. 39, no. 1, pp. 3-14, 2004. 